\title{
Pregnancy Related Skin Change
}

National Cancer Institute

\section{Source}

National Cancer Institute. Pregnancy Related Skin Change. NCI Thesaurus. Code C92856.

Alterations in the skin's appearance during pregnancy due to hormonal level changes. 